\title{
QUEEN'S
UNIVERSITY
BELFAST
}

\section{The Ontology of Thisness}

Diekemper, J. (2015). The Ontology of Thisness. Philosophy and Phenomenological Research, 90(1), 49-71. https://doi.org/10.1111/phpr.12010

Published in:

Philosophy and Phenomenological Research

Document Version:

Early version, also known as pre-print

Queen's University Belfast - Research Portal:

Link to publication record in Queen's University Belfast Research Portal

\section{Publisher rights}

This is the pre-peer-reviewed version of the following article: Diekemper, J. (2013), The Ontology of Thisness. Philosophy and Phenomenological Research.

doi: $10.1111 / \mathrm{phpr}$.12010, which has been published in final form at

http://onlinelibrary.wiley.com/doi/10.1111/phpr.12010/full. This article may be used for non-commercial purposes in accordance with Wiley

Terms and Conditions for Self-Archiving.

\section{General rights}

Copyright for the publications made accessible via the Queen's University Belfast Research Portal is retained by the author(s) and / or other copyright owners and it is a condition of accessing these publications that users recognise and abide by the legal requirements associated with these rights.

\section{Take down policy}

The Research Portal is Queen's institutional repository that provides access to Queen's research output. Every effort has been made to ensure that content in the Research Portal does not infringe any person's rights, or applicable UK laws. If you discover content in the Research Portal that you believe breaches copyright or violates any law, please contact openaccess@qub.ac.uk. 
This is the pre-peer-reviewed version of the following article: Diekemper, J. (2013), The Ontology of Thisness. Philosophy and Phenomenological Research. doi: 10.1111/phpr.12010, which has been published in final form at http://onlinelibrary.wiley.com/doi/10.1111/phpr.12010/full

\section{The Ontology of Thisness}

\section{JOSEPH DIEKEMPER}

\section{Introduction}

The primary goal of this paper is to investigate whether an ontology of thisness is forthcoming. Given some individual $x$, a thisness is the property of being $x$, or the property of being identical to $x$. Thisnesses - as I will be conceiving of them - are also primitive and purely non-qualitative properties; in other words, they are not instantiated by individuals derivatively or in virtue of standing in relations to other individuals, nor are they merely conjunctions of qualitative properties (see Adams 1979). In an earlier paper, I defended the existence of such properties — at least for a limited class of individuals (see Diekemper 2009); but here I am interested in investigating what it is for an individual $x$ to instantiate or exemplify its thisness. Although there has been a great deal of discussion in the literature both as to whether such properties exist, as well as to the use to which they can be put assuming that they do exist, there has been very little, if any, discussion about the ontological relationship between a thisness and the individual that instantiates it. ${ }^{1}$

Perhaps there is good reason for this lack of an ontology of thisness. Why, after all, should we suppose that thisnesses require their own ontology, distinct from that of qualitative

\footnotetext{
${ }^{1}$ I think this is a fair assessment. The most in depth contemporary discussion of the nature of thisness of which I am aware is Rosenkrantz (1993); but Rosenkrantz does not have much to say about the relationship between a thisness and its individual.
} 
properties? I offer two reasons for such a supposition now, though more reasons will arise in the course of the investigation. First, there is already a precedence for adopting distinct ontologies for thisnesses and for qualitative properties. Adams (1981) argues that although qualitative properties are to be conceived of on the Platonic model, i.e. as necessarily existing, thisnesses cannot be so conceived. His reasons for adopting this 'bifurcated realism ${ }^{2}$ have to do with considerations from modal actualism and its alleged incompatibility with necessarily existing thisnesses. I do not have the space to treat these arguments here, but I want simply to register that although I am (to my knowledge) the first contemporary philosopher to pursue an ontology of thisness in its own right, I am not the first to see the need for a distinction in one's ontology between qualitative properties and thisnesses (although, for reasons that I discuss below, I reject Adams' bifurcated realism).

Another reason for thinking that thisnesses require their own ontology is that they resist categorization under other common property kinds: they are like universals in that they seem to be abstract, and they are like essences in that they are essential to their bearers, but since they are also necessarily unique to their bearers, they are not universal! In their uniqueness, they are like tropes (conceived of as individual accidents), except that they are not accidental. So thisnesses are neither universals, nor mere essences, nor individual accidents; rather, they are individual essences; and, as such, it is not clear which category they fall under or how one ought to conceive of their ontology. I will say something more about the ontological distinction between universals and thisnesses in Section 2.2.

Although my primary goal here is to pursue an ontology for thisness, the methodology I will be employing in that pursuit will yield an important secondary goal as well. This is because my methodology will be to canvass three different, broadly Aristotelian, ontologies

\footnotetext{
${ }^{2}$ This is how Rosenkrantz (op.cit.) refers to Adams's realism.
} 
which might serve as models for an ontology of thisness. Given the differences between thisnesses and qualitative properties which I have just outlined, the models, of course, can only provide loose frameworks for a possible ontology of thisness. So I will need to consider the virtues of the models both as ontologies in their own right, and as models for an ontology of thisness. It may be that one model is best suited for thisness, and another best suited for the purposes it is meant fulfil, but I assume it is a desideratum of an ontology of thisness that it be structurally similar to that of qualitative properties, to the extent that their unique nature allows this. As I have just noted, this is where Adams's ontology of thisness bifurcates with his ontology of qualitative properties, since he thinks the latter are Platonic, necessarily existing entities, and he rejects this conception for thisnesses. For my part, I find Adams' arguments against Platonic thisnesses convincing, but given the desideratum above, and given independent reasons for preferring an Aristotelian conception of qualitative properties, I will not be considering the Platonist ontology, either in its own right or as a model for thisness. $^{3}$

Finally, I assume that at least some category/ies of entities have thisness, and I will be looking for a general account of how any entity or individual might instantiate thisness; but the models I will consider will focus specifically on material substances and their properties. This is because material substances are the most familiar-and are often taken to be the most

\footnotetext{
${ }^{3}$ Adams argues against necessarily existing thisnesses in Adams (1981, 1986); and Plantinga argues for necessarily existing thisnesses in Plantinga $(1976,1983)$. For fairly recent discussions of the debate, see Williamson (2002), David (2009), and Merricks (2011). All parties to this debate seem to assume that qualitative properties, at least, are Platonic; and no one offers an explanation of how a thisness conceived on the Aristotelian model might be related to its individual. In contrast, I will attempt to answer the latter question by assuming that qualitative properties are Aristotelian, and then by modelling thisness on such an ontology.
} 
fundamental - items of ontology, and so it makes sense to start the search for an ontological model for thisness by canvassing different substance ontologies. I will proceed first in Sections 1 and 2 by considering two different Aristotelian ontologies (the first due to Loux and the second to Lowe) as models; in Section 3, I will consider a hybrid Aristotelian ontology which combines aspects of both Loux's and Lowe's models; and finally in Section 4 I will arrive at some conclusions about the most apt ontology for thisness, as well as address the issue of how other kinds of entities (in particular events) might instantiate thisness.

\subsection{Loux's Aristotelian constituent ontology}

\subsection{The Ontology}

The first ontology I will consider is that according to Loux (2006), and it is based on Aristotle's account of substance in the Metaphysics. Loux argues that on this Aristotelian ontology, we should think of substances as being composed of more basic constituents, and, at least in the case of material substances, as composites of form (conceived of as Aristotle's 'primary substances', or what I will refer to as 'substantial universals') and matter.

Substances are instantiations of substantial universals by extended matter, and as such have internal structure. ${ }^{4}$ So a given substance, say, Rocky the cat, is a metaphysical composite of the matter of which Rocky is composed plus the substantial universal catness. On this view, substances do not instantiate substantial forms, since it is not the cat that instantiates catness; rather, it is the cat's matter that instantiates catness. Furthermore, since catness is a constituent of all cat substances, it is the constituent matter of each individual cat that serves to individuate them. According to Loux's rendering of Aristotle, this matter may, in turn, be

\footnotetext{
${ }^{4}$ Loux, following Aristotle, expresses the relationship between a universal and its bearer in terms of predication. According to Loux, Aristotle conceives of predication as a metaphysical relation between nonlinguistic objects, and not merely a semantic relation. I will continue to use the terminology of instantiation, though at times I will also speak of predication.
} 
the instantiation of a form by lower level matter. This process of matter being composed of more basic matter will eventually cease when we arrive at an original matter, i.e. 'a matter that has nothing else for its matter' (Loux, op.cit.: 230). For Aristotle, this may have consisted in the four elements (earth, air, fire, water), or some 'prime matter' which these four elements have in common. Presumably, however, this aspect of the theory could be updated by taking the microphysical constituents of matter to be ultimately basic. Whatever we determine as playing the role of original matter, since there is no more basic matter by reference to which the matter in question can be individuated, the individuating at this level must be done by spatiotemporal location (see ibid.: 232).

If substances are instantiations of substantial universals by matter, then what is the relationship between substances and their accidental universals? According to Loux, Aristotle holds that it is the substance itself which instantiates its accidental universals, and this results in a distinct ontological category which Aristotle calls a coincidental. So, for example, the cat, qua substance, is a composite of matter and catness; but the ginger cat, qua coincidental, is a composite of the cat qua substance and gingerness. Of course, Aristotle would acknowledge that the 'cat' and the 'ginger cat' refer to the same animal, but would simply claim that, qua substance and qua coincidental, the cat and the ginger cat (respectively) are distinct ontological entities. Loux explains that Aristotle recognizes two kinds of unity here: accidental unity and unity in being, where the latter is what we would call numerical identity. The composite that is the ginger cat is essentially (and trivially) ginger, but of course the cat is not essentially ginger - it might have been brown - therefore the unity that holds between the ginger cat and the cat is merely an accidental unity. This is to be contrasted with the unity that holds between the cat and itself (or between the ginger cat and itself), which is a unity in being (i.e. numerical identity). 
Perhaps surprisingly_ given its Aristotelian pedigree—on this account substantial universals are not instantiated essentially by their bearers, since the bearers are portions of matter, and any given portion of matter could have been informed by a different organizing principle (i.e. could have instantiated a different substantial universal). How, then, is the essential predication of kinds accommodated on this account? ${ }^{5}$ According to Loux, it is the relevant species universal which is essentially instantiated by a given substance. This instantiation is derivative to that of substantial universals and accidental universals, even though these are contingent. So the instantiation of substantial universals by matter and the instantiation of accidental universals by substances are both cases of primitive yet contingent instantiation; whereas the instantiation of species universals by substances is derivative but essential (see Fig. 1).

The advantage of this conception of universals and substances over the Platonic conception, according to which substances somehow 'participate in' or 'resemble' the universals which they exemplify, is that it makes it completely perspicuous what a substance is, and the role that universals play in the ontology of substances. This, indeed, is the advantage of any constituent ontology over what Loux, borrowing from Wolterstorff, calls a relational ontology: the relational ontology (of which the Platonic conception is one version) leaves it somewhat of a mystery as to what exactly is being related (i.e. substance and universal), and as to how they are related. One likely objection that the relational ontologist would make to this claim is to accuse the constituent ontologist of reducing substances to their constituents, and thereby deleting from the list of categories what is pre-theoretically the most fundamental item of ontology. The relational ontologist will acknowledge that there is not a lot that can be said about a substance and how it is related to the universals it

\footnotetext{
${ }^{5}$ Talk of predication here and elsewhere is meant to designate a metaphysical, not semantic, relation. See $\mathrm{n}$.
} 4. 
instantiates, but she will claim that this is to be expected if we conceive of substances as primitive and fundamental. But notice that the Aristotelian model I have sketched here is, as far as contemporary constituent ontologies go, minimally reductionist. It is only reductive in a very weak sense, since the reduction of substance to a composite of matter and substantial universal does not involve the reduction of its kind determining universal to more basic universals. According to Loux, this means that all and only the members of a particular substance kind $K$ have as a constituent a universal which determines that they are members of $K$, and this universal cannot, qua constituent of a member of $K$, be reduced or analyzed (ibid: 242).

Such a minimally reductive approach is to be contrasted with other constituent ontologies, which either reduce a substance's properties to its microphysical ones (such as in contemporary versions of the bare substratum theory) or claim that the only properties substances instantiate are the purely phenomenal ones (such as in bundle theories). Of course, as I mentioned above, there is the scope for reducing the matter that serves as one constituent of a substance to more basic matter, or to the microphysical constituents of matter, but this is not a reduction of substance, nor a reduction of substantial universals. So a substance is a composite of a plurality of constituents, but one of these constituents is metaphysically prior to the others and determines what the substance is (by being instantiated by the portion of matter which jointly constitutes the substance), and this kind determining universal is basic and unanalyzable. This picture provides a welcome balance between the relational ontology on the one hand, which fails to fully explain substances and the role of universals in an ontology of substance, and other constituent ontologies on the other hand, which reduce substances to something other than the familiar concrete objects of our experience. 
Before considering how this ontology might be employed as a model for thisness, I first want to consider an objection to the ontology — or rather, a cluster of objections which all have to do with the concept of immanence. One common objection to a substance ontology which includes Aristotelian universals is to wonder how a general feature-one that is shared and yet not divided — can be a constituent of a substance. On the present view, universals are immanent in the things that instantiate them, rather than existing outside space and time. Indeed, this aspect of Aristotelian universals is often cited as a virtue, since it avoids the mysteriousness of Platonic universals, which exist outside space and time, and which are thought by some to be explanatorily deficient on that account. ${ }^{6}$ However, inasmuch as universals are abstract objects, it cannot be the case that they are divided up in their instances, such that matter and substances only instantiate a part of the universals of which they are instances. ${ }^{7}$ So we must say that universals, on this view, are wholly located in each of their instances; and yet one and the same universal can have indefinitely many instances at any point in time. As Lowe points out in his critique of this conception of universals, we seem to lose our grip on the concept of spatiotemporal location when we claim that one thing is wholly located in numerous places at the same time. ${ }^{8}$ There are no other entities, according to Lowe, about which we would allow a similar claim, so why should we allow that universals are any different? To answer this question by simply asserting that universals are different fails to illuminate the problem. We want to know how any kind of entity can have

\footnotetext{
${ }^{6}$ See, for example, Lowe (2006: 98).

${ }^{7}$ See Hoffman, J. and Rosenkrantz, G., (2003: 54).

${ }^{8}$ See Lowe (2006: 98-99). For my part, I take Lowe's objections to count against phenomenal properties only, and not against substantial universals, which are formal organizing principles (see below).
} 
maximal, multiple, but discontinuous spatial locations at the same time. Absent such an explanation, Loux's constituent ontology is reduced in its explanatory power.

Perhaps, however, this gets the ontology wrong. Perhaps we should not gloss immanence as a claim about universals themselves, but as a claim about their instances. So, although universals have instances in space and time, they are not themselves in space and time. Unfortunately this will not get us very far, since it is not clear how this account of 'immanence' is able to avoid the transcendence of Platonic universals. As a matter of fact, Lowe (2006: 98-99) argues that the concept of immanence, as employed in this context, is either incoherent (for reasons given in the previous paragraph) or amounts simply to the instantiation of particularized properties. If properties really are immanent and wholly located in their instances, then they must be particulars, since only particulars can have a particular location in space and time. Lowe therefore endorses an ontology according to which a substance's accidental properties are particular instances of accidental universals.

We will consider this ontology in Section 2; but I want to flag the relevance of the distinction between substantial universals and accidental universals in this context.

Substantial universals are formal principles of organization which inform the matter in which they are instantiated, whereas accidental universals are phenomenal properties of substances. The relevance of this distinction in the current context is this: the objections from immanence are more pressing for accidental universals than they are for substantial universals. To see why this is the case, consider that phenomenal properties can be demonstrably referred to while organizing principles cannot. I can point to the blue in my shirt and say, 'Look at the blueness of my shirt.' I cannot, however, point to Rocky's catness and say, 'Look at Rocky's catness.' I can indirectly refer to Rocky's catness by demonstrably referring to those accidental universals of his which characterize his catness; but, as we have seen, catness is not reducible to these. Given these considerations, it is more difficult to conceive of a 
phenomenal property, such as blueness, being wholly present in multiple locations at the same time, than it is to conceive of a formal organizing principle such as catness informing distinct portions of matter at the same time. In the latter case, we feel very little conceptual pressure to question how the very same principle could wholly inform distinct portions of matter, since a principle is a paradigm case of an abstractum. Of course, blueness here is supposed to be an abstract object as well, but the problem is that it does not appear that it can be when it is immanent in a substance. So, given our concept of spatiotemporal location, we do feel conceptual pressure to question how the very same blueness can be wholly present in two distinct substances. I take it, then, that the objections from immanence are meant to count against accidental, not substantial, universals. That, at any rate, is how I intend them.

\subsection{Loux's ontology as a model for thisness}

Having considered Loux's ontology on its own terms, we now need to evaluate it as a model for thisness. We should note at the outset, however, a feature of Loux's ontology that may bear on any conclusions we might make regarding thisness. Given the individuating role that matter plays in the ontology, and given that, on this ontology, matter instantiates substantial universals in a primitive, irreducible way, we may find that the model renders the positing of thisness redundant. We will return to this point at the end of this section.

In trying to adapt Loux's ontology for an ontology of thisness, we need to consider where among the different categories of properties in the model we should situate thisness. Our three choices are i) substantial universals; ii) accidental universals; and iii) species universals (see Fig. 1). Once again, thisnesses do not strictly align with any of these categories, but we should evaluate which of the three aligns most closely with thisness, and then make necessary adaptations to the model to accommodate thisness. With respect to i), substantial universals are organizing principles which inform the matter that instantiates them. They are instantiated primitively, yet contingently, and they are constituents of, or 
ingredients in, their substances. Thisnesses are also instantiated primitively, but they are individuating — not organizing — principles, and they are not constituents: they are instantiated not by matter but by substances themselves. If we did claim that they were instantiated by matter in order to accommodate this model, we would have to claim that, e.g., Rocky the cat's matter had the property of being identical to Rocky. But that is a property that belongs to Rocky, and not to his matter. Furthermore, thisnesses are essential properties, and, on the current model, substantial universals are not essential, since they are predicated of matter, not of substances. So there are several respects—-some quite drastic — in which we would have to deviate from the ontology in order to model thisnesses on i).

With respect to ii), accidental universals are also primitively instantiated, but they are predicated of substances rather than matter, so on that score they fair better than i). However, just as with i), they are not essential to their bearers (they are accidental!). This strikes me as a rather benign disanalogy though, since there is nothing about their place in the ontological framework which requires that they be contingently instantiated; it is, rather, a consequence of the nature of material substances (i.e. that they can undergo qualitative change without undergoing substantial change). So there is scope here to slot thisnesses into the ontological position held by accidental universals, with the caveat that the former, unlike the latter, are essential properties. In this case we would also have to remove the part of the framework involving the composition of coincidentals by accidental universals and substances, since it's not clear that substances and their thisnesses together compose some distinct entity (see Fig. 2).

Moving on to species properties, they are both essential and predicated of substances. These universals, however, are instantiated by substances in virtue of the substance being a composite of matter and the species determining substantial universal. This is what Loux, following Aristotle, means by saying that the species universal is instantiated derivatively but 
essentially: given that a particular portion of matter contingently instantiates its substantial universal, the resulting substance is essentially a member of the species which corresponds to that substantial universal. So the substance could not exist and fail to be a member of its species, but this is only because the substance's matter instantiates the relevant substantial universal, and when it (i.e. the matter) ceases to instantiate that universal, then the substance ceases to instantiate the species universal: that is to say, the substance ceases to exist. This is a case of what Aristotle calls substantial change, and on the current account, substantial change is fundamentally a case of the matter of a substance beginning or ceasing to instantiate a substantial universal, and it is only derivatively a case of the substance beginning or ceasing to instantiate its species universal. So how does all this bear upon the question of whether or not the role played by species universals in Loux's ontology is a suitable one on which to model thisness? The limitation of that role vis-à-vis thisness is that a substance instantiates its species universal derivatively, and as we have seen, thisnesses are instantiated primitively. As with i), I think the adjustment required to model thisness after the role played by species universals in Loux's ontology would be too drastic. This is because the derivative nature of species universals is a consequence of their place in the ontological framework, and as such it would not be plausible to suggest that properties modelled after species universals were instantiated primitively.

It appears, then, that in determining which aspect of Loux's ontology we might model thisness on, accidental universals best fit the bill, given that the adjustments attending that suggestion depart least from the original ontology (see Fig. 2). There remain, however, some issues with this suggestion. Earlier I claimed that one of the advantages of an Aristotelian ontology over the Platonic ontology was that the former offers a more powerful explanation of the relation between a substance and its properties: properties are immanent in their substances, as opposed to being transcendent to them. In addition, I would claim that 
immanence is a characteristic to be desired in thisnesses, since, arguably, it better accounts for their individuating role. Thisnesses are supposed to capture the particularity of the individuals that have them, but if thisness is not immanent in an individual, how can it do the work it's supposed to do, i.e., individuate this particular individual? If thisnesses are transcendent to the individuals that have them, then it seems that we have particularity on the cheap. Of course, this is not a relevant concern if we are only interested in properties as universals, because then particularity is not an issue (universals are general or common features), but thisnesses are not general features, they are essentially and uniquely a feature of an individual $x$, and it is far more plausible that such a feature be immanent in $x$ rather than transcendent to $x$. Now, in the case of Loux's ontology, immanence is captured in terms of constitution: substantial universals are constituents of substances, and accidental universals are constituents of coincidentals. ${ }^{9}$ Given, however, that thisnesses cannot plausibly be conceived of as constituents of substances (since this would require that they be predicated of matter, and Rocky's matter does not have the property of being identical to Rocky), nor as constituents of coincidentals (since there is nothing coincidental about a substance's instantiating its thisness), on the present model they are not constituents of anything. This, once again, allows a certain degree of mysteriousness to pervade the account, since it leaves us wondering what it is for a thisness to be immanent in a substance.

There is a further, related complication in modelling thisness after Loux's ontology. We want thisnesses to be immanent in the individuals that instantiate them, in order to capture their individuality; but we may also want to say that thisnesses - though ontologically dependent on their individuals' coming into existence-continue to exist even after the demise of their individuals. Call the claim that the thisnesses of future individuals do not

\footnotetext{
${ }^{9}$ Though, as we saw above (Section 1.1), this account of immanence still does not address the problem of how one accidental universal can be a constituent of many different particulars at the same time.
} 
exist, but the thisnesses of past individuals do exist, the Time and Thisness Thesis (TTT). Adams (1986) argues for TTT, and I defend and elaborate on the thesis in Diekemper (manuscript). Suffice it for our purposes here to note that if one endorses an objective, ontological asymmetry between the past and future (as I do), then TTT is a highly attractive thesis. ${ }^{10}$

Now, given the immanence of Aristotelian universals and their ontological dependence upon their instances, it is standard to adopt a principle of instantiation for such universals which reflects one's preferred theory of time. So, for example, Armstrong (1999: 198), who has an Aristotelian theory of universals and an eternalist theory of time, endorses what he characterizes as a 'relatively liberal form' of the principle, according to which it ranges over all times. Thus, according to Armstrong, every universal must be instantiated at some time, but not necessarily at the present time. Loux, on the other hand, following after Aristotle (whom he takes to be a presentist), endorses a tensed principle of instantiation according to which every universal must be instantiated at the present time. If, however, we are using Loux's ontology as a model for thisness, and we endorse TTT, then our principle of instantiation for thisness will assert that all thisnesses must either be presently instantiated, or have been instantiated in the past. And now the complication becomes evident, since it is not clear how that principle of instantiation is possible, inasmuch as it is not clear how a thisness which is immanent in an individual can survive that individual's demise. This, however, is only a complication for those who feel compelled to endorse TTT.

Finally, what of the issue of redundancy, which I raised at the beginning of this subsection? I refer the reader again to Fig. 2, in which I have modeled thisness on the accidental universals of Loux's ontology (with some adjustments). Consider that matter is still an

\footnotetext{
${ }^{10}$ I defend such an ontological asymmetry in Diekemper (2005).
} 
essential part of this model, and that it features at a more fundamental level in the model than does thisness. It appears, then, that thisness is not bringing anything additional to the model that is not already provided by the constituent account of substantial particulars. I say 'appears,' because ultimately that claim depends upon whether one thinks that matter can individuate, and, in particular, whether matter can individuate across possible worlds. We will return to this issue in Section 3, but for the moment I will simply record the thought that if matter can, indeed, individuate across possible worlds, and if one wished to endorse Loux's Aristotelian constituent ontology, then it would be superfluous to also endorse thisness, at least in the case of material substances.

\subsection{Lowe's Aristotelian four-category ontology}

\subsection{The Ontology}

We now turn to Lowe's (2006) 'four-category' ontology, which he derives from Aristotle's Categories. ${ }^{11}$ According to this ontology, substances just are instantiations of substantial universals. Matter does not play an essential role in this ontology, and substances on this view are not to be conceived of as composite entities which can be further analyzed in terms of their constituents. As for accidental universals, Lowe also acknowledges these, but denies that they are instantiated by substances; rather, substances are 'characterized' by particularized properties (i.e. tropes, or what Lowe calls 'modes'), which in turn are instantiations of accidental universals. ${ }^{12}$ Lowe takes these modes to be the 'individual accidents' or 'nonsubstantial individuals' of Aristotle's Categories. ${ }^{13}$ Although Lowe

\footnotetext{
${ }^{11}$ See Lowe (2006: Chs. 6-7) and Lowe (2000).

${ }^{12}$ Lowe variously refers to accidental universals as 'attributes,' 'properties' and 'non-substantial universals,' but for the sake of consistency with Section 1, I will continue to refer to these as accidental universals.

${ }^{13}$ Lowe is not alone in taking these items to be particularized, nonrecurrent properties, see also Mulligan (et al) (1984) and Wedin (2000: Ch. 2).
} 
intends for his modes (Lowe credits Locke with the term) to be co-extensive with what most contemporary philosophers would call 'tropes,' he avoids the latter term in view of its association with nominalism and the trope bundle theory, for Lowe's ontology is a thoroughly realist one. Furthermore, he rejects the trope bundle theorist's characterization of particularized properties as constituents of material objects. Modes, rather, are individual instantiations of accidental universals which characterize a substance and which ontologically depend upon that substance.

Lowe refers to the ontological dependence of a mode upon its substance as rigid, in order to capture the idea that, necessarily, the existence of the substance is a necessary condition for the existence of the mode (see Lowe, op.cit.: 34-6 and 116-17). Accidental universals, in turn, ontologically depend upon their individual instantiations (their modes), but they do so only non-rigidly. This is because it is not necessarily the case that the existence of any particular mode is a necessary condition for the existence of its accidental universal. An accidental universal exists only if there is at least one instance of it, and there may be many instances of the accidental universal in question. However, in the possible world in which a given mode is the only instance of its accidental universal, then, in that world, the existence of the mode is a necessary condition for the existence of the universal (thus the non-rigidity of the dependence). So for Lowe, accidental universals are general 'ways things are', whereas modes are particular 'ways things are.' Substantial universals, on the other hand, are 'what things are.'

Thus Lowe's ontology posits four fundamental, interrelated categories: substances (or 'substantial particulars'), substantial universals, modes and accidental universals (see Fig. 3). These categories stand in various formal relationships with one another: substances and modes instantiate (respectively) substantial universals and accidental universals; accidental universals and modes characterize (respectively) substantial universals and substances; and 
substances exemplify accidental universals. The relationship of exemplification is a derivative one which holds in virtue of two different basic relationships: i) a substance exemplifies an accidental universal in virtue of being characterized by a particular instantiation of that universal (i.e. a mode); and ii) a substance exemplifies the accidental universal in virtue of being an instantiation of a substantial universal which is characterized by the accidental universal. So a violet exemplifies blueness both in virtue of being characterized by its particular blueness, which, in turn, is an instance of the universal blueness; and also in virtue of being an instance of the violet kind, which in turn is characterized by the universal blueness.

Why does Lowe think that both accidental universals and modes are required for an adequate ontology? Recall Lowe's criticism of immanent realism in Section 1.1, above (an objection which I took to count against Loux's accidental—not substantial—universals). As we saw there, Lowe thinks that the notion of immanence is highly problematic, since it is either conceptually incoherent (in that it allows the inexplicable violation of our concept of spatiotemporal location), or it amounts to nothing more than the positing of particularized properties. Since Lowe agrees with the constituent ontologist that the Platonic notion of transcendent and necessarily existing universals should be jettisoned, he thinks that the only coherent way to allow for this is by positing both universals and modes. Only by doing so can we coherently and adequately explain the causal and perceptual relevance of universals. Thus it is the particular instantiations of accidental universals which are causally relevant and which account for our knowledge of the qualities of substances. On this model, when I see the blueness of a violet, I am not seeing an abstract universal, I am seeing a particular, concrete instantiation of an abstract universal: i.e., the particular blueness of this particular flower. 
With respect to the nature of substances, Lowe thinks that he has accommodated both the Aristotle of the Categories - by claiming that individual concrete things are the primary substances - and the Aristotle of the Metaphysics — by allowing that particular substantial forms (or universals) are the primary substances; this is because he thinks individual concrete things just are instances of substantial forms (Lowe 1998: 209). So individual concrete things serve what are normally thought to be distinct ontological roles: they are both instantiations of universals, and that in which the universal is instantiated. ${ }^{14}$ This approach certainly does justice to the idea that substances are fundamental to ontology, and therefore that a substance ontology should treat them as primitive and irreducible. If, however, one thought it a desideratum of a substance ontology that it be able to provide an account of what the relationship between a substance and its substantial universal amounts to, then one might find Lowe's substance ontology unsatisfying; for, according to Lowe, there is nothing more to say than that a substance just is an instantiation of a substantial universal. But one is left wondering what it is for a substance to be such a thing, and to instantiate such a universal. Lowe, of course, thinks that this is what a non-reductive account amounts to, and to analyze substances further would force an unacceptable reduction of substances. But as we saw in Section 1, if one desired a more thoroughgoing analysis of what a substance is, with only very minimal and ontologically benign reductive ramifications, then Loux's constituent ontology seems to fit the bill.

\subsection{Lowe's ontology as a model for thisness}

\footnotetext{
${ }^{14}$ I say 'normally thought' because one need not conceive of substantial universals and substantial particulars as two different ontological categories. One might, instead, think of these as two different ways of looking at individual concrete things (I thank Anna Marmodoro for this point). Lowe, however, does conceive of them as distinct categories (thus the 'four category ontology').
} 
So although Lowe's ontology solves the immanence problem faced by Loux's model, in so doing it stops short of a complete analysis of what a substance is. It does, however, provide a promising model for thisness (again, with some modification), inasmuch as it postulates a two step model of how substances 'exemplify' accidental universals. Again, they do so in virtue of being characterized by modes which, in turn, are instantiations of accidental universals. ${ }^{15}$ This two step model of exemplification is a promising one for thisness because it has the resources to capture the idea that thisnesses are individual essences. Recall from the introduction that thisnesses resist categorization because they are like tropes (or Lowe's modes) in their individuality, but inasmuch as they are essences they are like abstract properties; so they are a sort of cross breed between universals and tropes (or modes). Now, in view of Lowe's two step exemplification ontology, we can claim that there are both thisness properties and thisness modes, thus accounting for both aspects. Thus, for a given a substance $\mathrm{x}$, we have the abstract thisness property being identical to $x$, and the thisness mode, which is the particular instantiation of being identical to $x$.

Adapting Lowe's ontology for these purposes requires the following modifications. First, since Lowe's ontology has it that only accidental universals participate in this two step exemplification process, and not substantial universals (for the obvious reason that substantial universals are not individual), we must consider thisnesses on the model of accidental properties. Just as in the case Loux's ontology, however, this is a benign substitution, since there is nothing in Lowe's ontological framework which entails that essential properties cannot participate in the two step exemplification process. Second, since substantial

\footnotetext{
${ }^{15}$ Of course, as we saw in section 2.1 above, according to Lowe, a substance also exemplifies an accidental universal in virtue of being an instantiation of a substantial universal which is characterized by the accidental universal. For reasons that will become clear, however, this cashing out of the exemplification relationship is not as relevant in the context of providing a model for thisness.
} 
universals play no role in the thisness model (remember, substantial universals are qualitative, whereas thisnesses are not), they fall out of the model. Finally, we do not want to claim that the thisness modes characterize substances (as in the original ontology), since, again, this is what qualitative properties do; rather, we should replace this relationship between a substance and its thisness mode with one of individuation: a thisness mode individuates its substance. So according to the model, a substance exemplifies its thisness property in virtue of being individuated by its thisness mode, which in turn is an instantiation the thisness property (see Fig.4).

Notice that this model is able to deal with the two issues faced by the previous model derived from Loux's ontology (see section 1.2). Those two issues were i) that the model was unable to give an account of the immanence of thisness, and therefore that it could not capture the particularity of thisness; and ii) that the model was unable to allow for the possibility that thisnesses might survive the demise of their individuals (as in Adams's TTT). On the present model, however, the particularity of thisness is captured by the particular instantiation of a thisness property by a thisness mode. The latter thus individuates a substance by being immanent in it. What is it for a thisness mode to be immanent in its substance? It cannot be on the model of a qualitative mode's immanence in its substance since, as we saw, that immanence accounts for our perception of qualities in substances, and thisness modes cannot be perceived as qualitative modes can. But if we think of an individual $x$ 's thisness property $F$ as a formal principle of individuation for $x$, and $x$ 's thisness mode $F^{*}$ as the (unique) particular instantiation of that principle, then $F^{*}$ is the individuating principle of this particular individual $x$. The thought is that for the principle to do the individuating work it does in some particular spatiotemporal entity, it must have the same spatiotemporal status, at least as long as the entity exists. Furthermore, although the thisness mode is in its substance, in keeping with Lowe's conception of a mode, the thisness mode is 
not a constituent of the substance, since a composite entity is ontologically dependent upon its constituents. The thisness mode, conversely, is rigidly ontologically dependent upon its substance (i.e., necessarily, the thisness mode exists only if the substance exists).

The thisness property, in turn, ontologically depends upon the thisness mode-but in this case (as in Lowe's original model), the ontological dependence is non-rigid. Recall that in the case of the ontological dependence of accidental universals on modes, the non-rigidity of that formal relationship was meant to capture the idea that accidental universals only depend upon a single instance for their existence, not on all such instances. In the case of thisness properties, however, they necessarily have one and only one mode, so why maintain that this ontological dependence is non-rigid rather than rigid? The reason is to allow the theory to cope with issue ii), specified above. If our model of thisness is to make sense of Adams's TTT, then it needs to allow for the existence of thisnesses of past individuals. The thisness mode is a particular property which rigidly ontologically depends upon its substance, so when the substance ceases to exist, so does the thisness mode. The thisness property, however, is an abstract — not a particularized — property, so it will continue to exist even after the thisness mode upon which it ontologically depends ceases to exist. Thus we have to specify an ontological dependence whereby the existence of a thisness property $F$ depends upon its thisness mode $F^{*}$ having come into existence, but not necessarily existing now. I take it that this is also a kind of non-rigid ontological dependence, but where the non-rigidity is temporal rather than modal: that is, there is some time at which $F$ ontologically depends upon $F^{*}$ 's existence, but it does not do so at all times (just as in Lowe's modal, non-rigid ontological dependence, there is some possible world at which an accidental property ontologically depends upon a particular one of its modes, but it does not do so in all possible worlds). 
According to this ontological framework, when a substance $x$ begins to exist at a time $t$, both its thisness mode $F^{*}$ (which individuates it) and its thisness property $F$ (of which $F^{*}$ is an instance) also begin to exist. Upon x's demise, $F^{*}$ also ceases to exist, but $F$ continues to exist. I take this model to be a promising one which we will return to in Section 4. Before moving on, however, I want to note an implication of conceiving of thisnesses as formal individuating principles. Doing so bolsters the motivation for providing a distinct ontology of thisness. This is because, on such a conception, thisnesses cannot be subsumed under the same category as either accidental or substantial universals. As we have seen, the former are phenomenal and susceptible to demonstrative reference, whereas thisnesses, like substantial universals, are formal principles and therefore not so susceptible. Substantial universals, however, are organizing principles, whereas thisnesses are individuating principles, and they therefore play a distinct ontological role to that of substantial universals. Thus the need for a distinct ontology for thisness.

\subsection{A hybrid Aristotelian ontology}

In this section I want to consider one final substance ontology — both on its own, and as a model for thisness. The ontology I will present here is one that is not currently represented in the literature; it is, in fact, a hybrid Aristotelian ontology which combines aspects of both Loux's and Lowe's ontologies. Given that we have already covered its predecessors in depth, it will not take long to present the ontology and discuss its suitability as a model for thisness.

\subsection{The ontology}

My reason for desiring to pursue a hybrid ontology is to attempt to avoid the objections I raised to its predecessors. To recapitulate those objections: Loux's ontology was unable to offer a coherent account of immanence, and Lowe's ontology did not provide a thoroughgoing analysis of substance (even though, as we have just seen, Lowe's ontology did 
provide a good model for an ontology of thisness). ${ }^{16}$ In order to dispel both of these objections, I suggest a hybrid ontology according to which substances are to be conceived as on Loux's ontology (i.e. composites of matter and substantial universal); but accidental universals are to be related to their substances as in Lowe's ontology (see Fig. 5).

According to the hybrid ontology, a portion of matter instantiates a substantial universal, which together constitute a substance. The substance, in turn, is characterized by particular instantiations of accidental universals, but these are not constituents (so there are no coincidentals composed of substances and accidental properties on this ontology). On this view, substances ontologically depend upon their constituents of matter and substantial universals (in the way explained in Section 1.1), contrary to Lowe's conception of substance. The hybrid ontology, however, mirrors Lowe's in all other respects and includes the same formal relationships of characterization and exemplification. This ontology offers a thoroughgoing analysis of what it is to be a substance, with only very minimally reductive consequences; and it offers a coherent and empirically satisfactory account of the immanence of accidental universals.

\subsection{The hybrid ontology as a model for thisness}

Although the hybrid substance ontology is able to deal effectively with what I take to be the weaknesses of its predecessors, how does it fare as a model for thisness? Were we to develop the model along the same lines as in previous sections, it would look very much like the model developed from Lowe's ontology (Fig. 4), with the exception that the substantial particular which is individuated by its thisness mode would itself be composed of matter and

\footnotetext{
${ }^{16}$ The extent to which one takes this as an objection will, of course, depend upon whether one takes a thoroughgoing analysis of substance to be a desirable thing. My point has simply been that if we can analyze substance further without completely reducing it away, then we should do so.
} 
substantial universal. Would this exception make for a material difference between Lowe's model and the hybrid model? In fact, I believe it would. Recall during the assessment of Loux's ontology as a model for thisness (Section 1.2), we were left wondering what need have we for thisness if the constituent matter of a substance $x$ can play the role of individuation for $x$. As a matter of fact, I think that matter probably can play this role. I argue in Diekemper (2009) that the Max Black style, spatial dispersion arguments which are commonly used to argue against the thesis that matter and spatial position can individuate across possible worlds are not successful in that endeavour. However, I also argue that the analogous temporal dispersion arguments, which are meant to show that temporal position cannot individuate, are successful. These conclusions imply that material substances do not, and events do, have thisness. So although I think some entities have thisness (such as events), material substances in all likelihood do not. Why, then, did I choose material substance ontologies as potential models for thisness, if I do not believe that material substances have thisness? It is because substance ontologies are, quite rightly, the most developed of all ontologies, and because they are capable of serving as models of instantiation for a variety of ontological kinds.

So although the hybrid ontology, as a model for thisness, makes thisness redundant in the case of material substances, this is perfectly consistent with my own views on thisness. I conclude that although the hybrid ontology, as a substance ontology in its own right, is to be preferred among the other ontologies considered, it is not suitable as a model for thisness. Given that it is superfluous to postulate the instantiation of thisness by any entity which has matter as an essential constituent, a model for thisness should not have matter as an essential aspect of the model.

\subsection{An ontology for thisness}


I therefore endorse the model developed in Section 2.2 (Fig. 4) as the best model for an ontology of thisness, with the understanding that 'Substantial particulars' in that model should be replaced with the general term 'Individuals.' Further, since I take it that events, at least, are not essentially spatial or material entities and do require thisness for their individuation, I would like to make some programmatic remarks about how the ontology in Fig. 4 lends itself to describing the instantiation of thisness in these entities.

According to this ontological framework, a thisness property $F$ is exemplified by an individual $x$ in virtue of having a particular instantiation (its mode) $F^{*}$ which individuates $x$. $F$ comes into existence at the same time that $F^{*}$ begins to individuate $x$ (i.e. when $x$ begins to

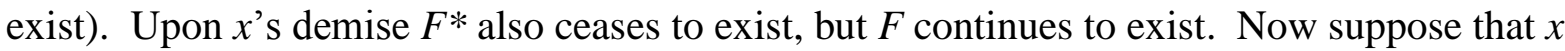
is an event (call it $e$ ): $e$ comes into existence when it occurs at time $t$ (I assume here the temporal ontology implied by Adams's TTT), as does its thisness mode $F^{*}$ which rigidly, ontologically depends upon it. $e$ 's thisness property $F$ also comes into existence at $t$, but since its ontological dependence upon $F^{*}$ is non-rigid, it (i.e. $F$ ) will continue to exist even after $e$ is no longer occurring. So when $e$ ceases to occur at some time later than $t, F^{*}$ ceases to exist, but $F$ does not. And now we can see that this framework is particularly apt in the case of a temporal ontology according to which the past exists and the future does not, since the continued existence of $e$ 's thisness property $F$ provides a ground for the existence of $e$, even though $e$ is no longer occurring. ${ }^{17}$

What should we make of $F^{*}$ 's relationship to $e$ ? I began to address this question in Section 2.2 (above), but I would like to say something more about it in the context of an ontology of thisness for events. There I claimed that a thisness mode $F^{*}$ individuates its individual $x$ by being a particularized, spatiotemporal instance of $x$ 's principle of

\footnotetext{
${ }^{17}$ I defend this conception of past existence in Diekemper (manuscript).
} 
individuation. But what is this particularized principle other than the particularized property of being identical to $x$ ? And what, in turn, is this, other than simply $x$ itself? The thought is that a particularized, spatiotemporal instance of being identical to $x$ is none other than $x$ ! This characterization of the thisness mode, as simply being the individual that it individuates, would have been redundant in the case of material substances (given a constituent ontology of material substances), but in the case of events it is far more plausible, given that there are extant theories of events which take events to be instantiations of tropes. ${ }^{18}$

In order to make this suggestion work - the suggestion that the thisness mode of an event just is the event — one would have to develop a theory of events such that the theory cohered with the ontology of thisness suggested here. ${ }^{19}$ I take it that this is a general point about the role of the ontology of thisness: although it presents a plausible framework for the instantiation of thisness in any kind of individual, it cannot stand alone, but must be applied in conjunction with an appropriate ontology for the kind of individual in question. This was the lesson from the case of material substances, since the ontology of substances that I ended up endorsing was not one which provided a good fit with the ontology of thisness. Suppose that persons are not conceived of as essentially material entities, and suppose that they too require thisness for their individuation; then an application of the ontology of thisness to persons would also have to be carried out in conjunction with a worked out theory of persons. Clearly, however, this is not the place to begin working out theories of events or persons.

\footnotetext{
${ }^{18}$ For two such theories see Bennett (1988) and Cleland (1991).

${ }^{19}$ In Section 2.1 (above) I took issue with Lowe's characterization of a substance as simply being an instance of a substantial universal, claiming that it did not provide a thoroughgoing analysis of substance. Could the same objection be made to my suggestion that an event is simply a thisness mode? Again, this would depend on one's theory of events, but given the primitive, non-qualitative character of thisness, I do not think the two claims are of a piece.
} 
What I have tried to develop here is a general framework for the relationship between an individual and its thisness. Inasmuch as the ontology in Fig. 4 grounds both the individuating role of thisness and its temporal structure (assuming Adams's TTT), it provides the framework required.

\section{Conclusion}

To sum up, I have argued first, that a hybrid Aristotelian ontology according to which substances are to be conceived as composites of matter and substantial universal, but accidental universals are to be related to their substances via a two step exemplification structure (as in Fig. 5), is to be the preferred substance ontology; and second, that the preferred ontology for thisness is one according to which an abstract, thisness property is exemplified by an individual $x$ in virtue of having a particular instantiation (its mode) which is immanent in and which individuates $x$ (as in Fig. 4). 


\section{FIGURES}

Fig. 1: Loux's Aristotelian constituent ontology:

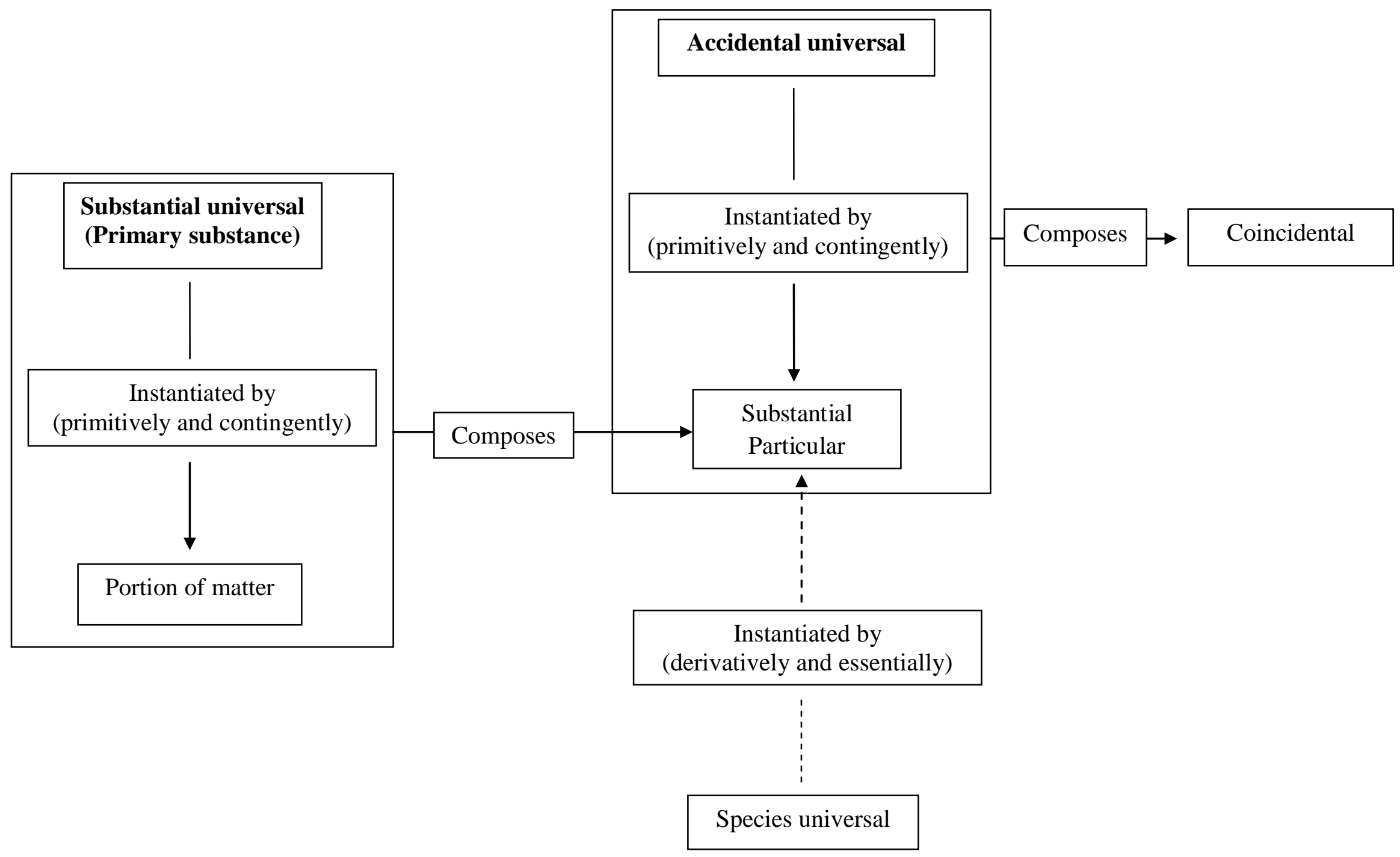

Species universal 
Fig. 2: Thisness model derived from Loux's ontology:

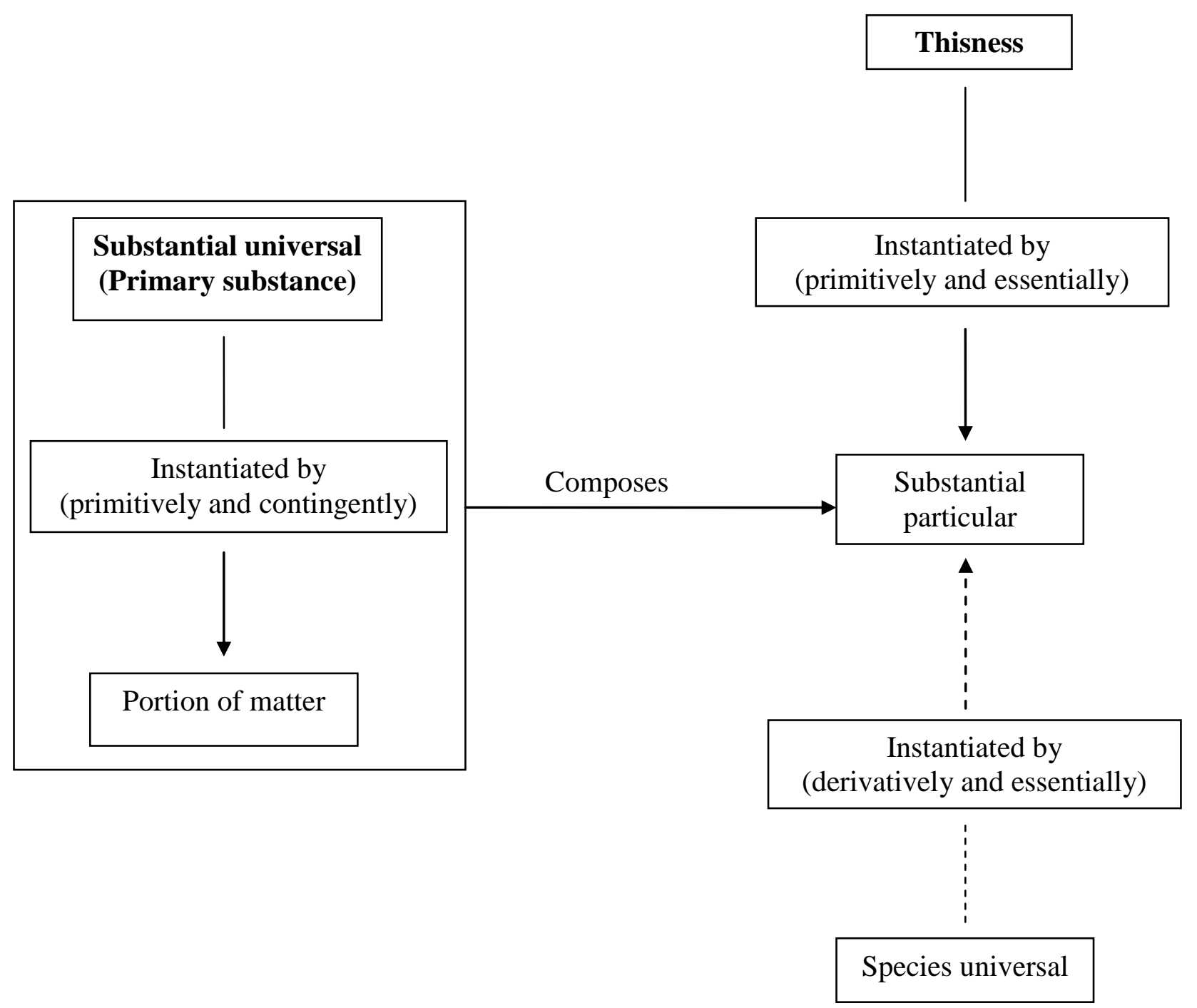


Fig. 3: Lowe's Aristotelian four-category ontology ('the ontological square', see Lowe 2006: 93 and 111):

Substantial universals (kinds)

Characterized by Accidental universals

(s)
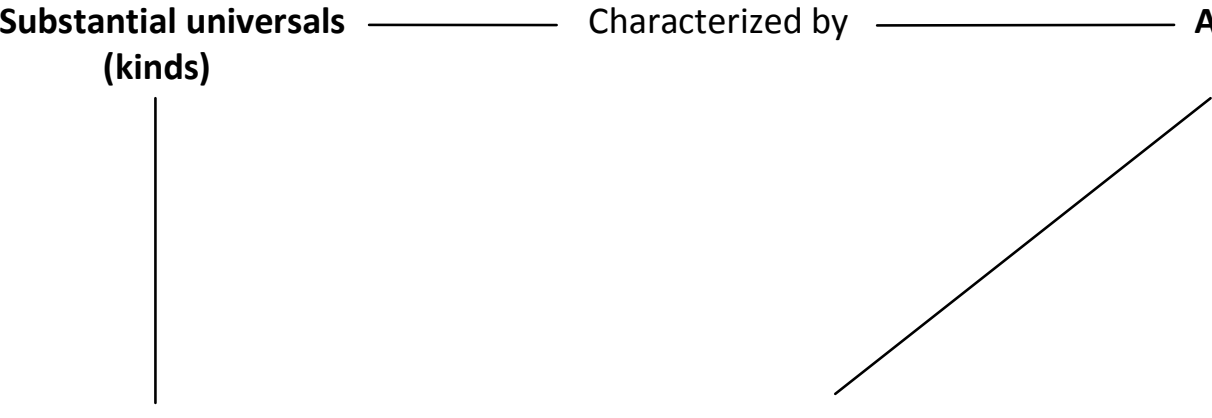

Instantiated by Exemplified by (properties)

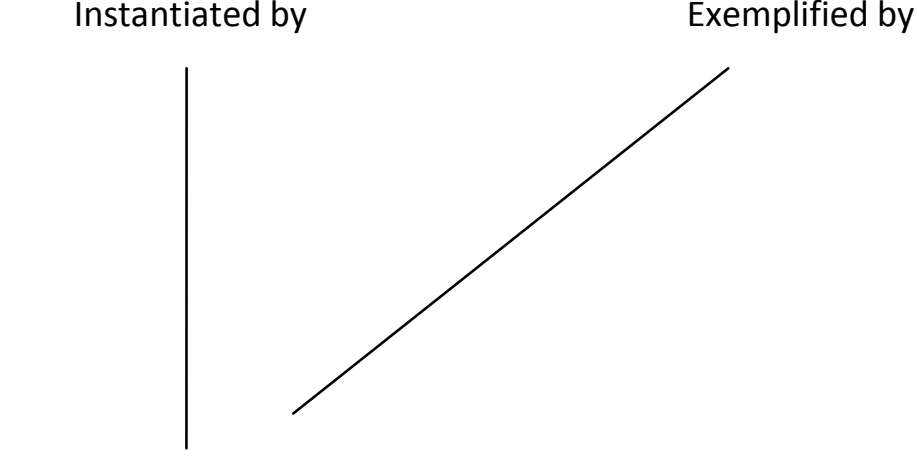

Substantial particulars

Characterized by

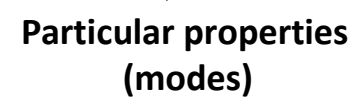

(objects)

Fig. 4: Thisness model derived from Lowe's ontology:

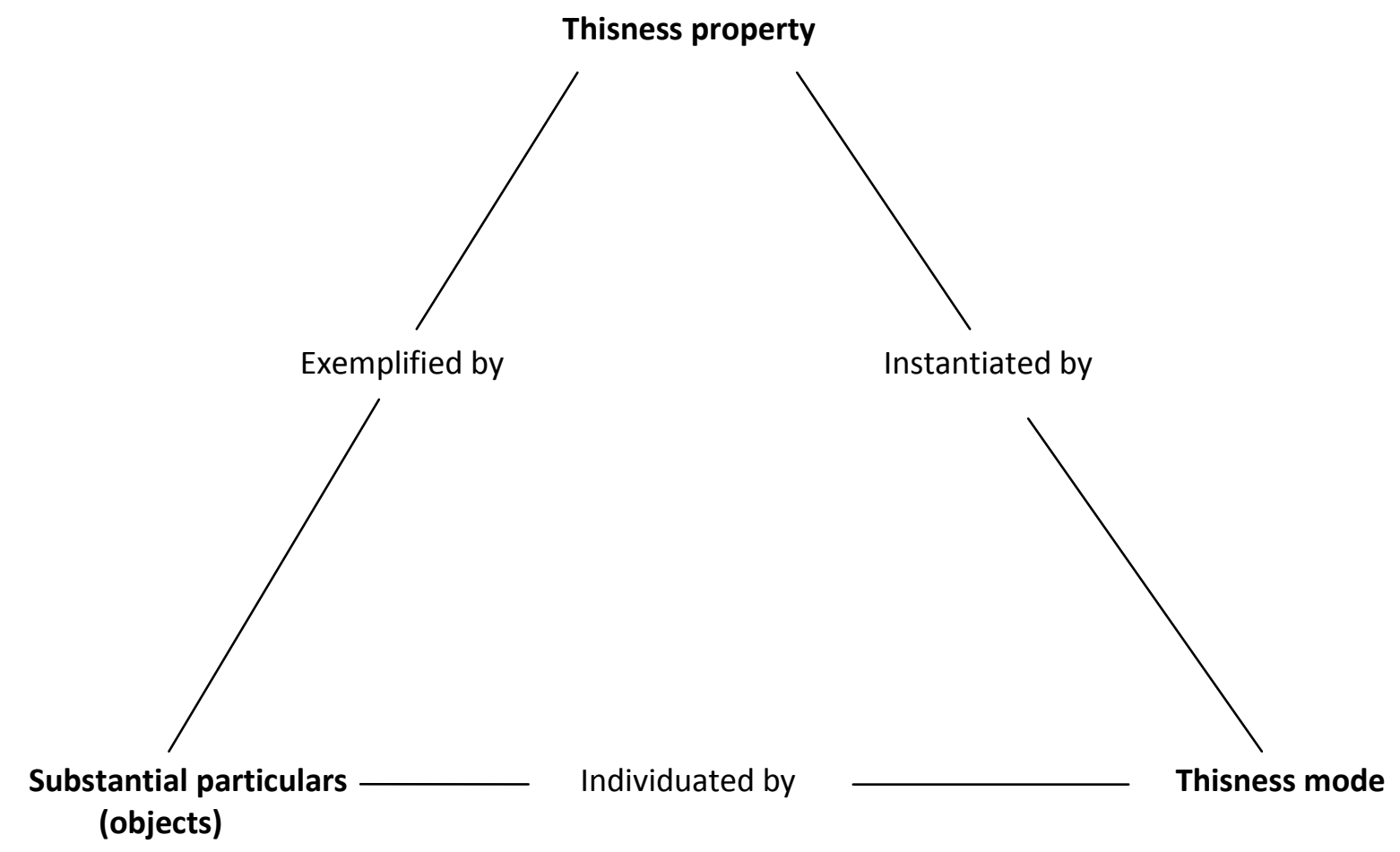


Fig. 5: Hybrid Aristotelian ontology:

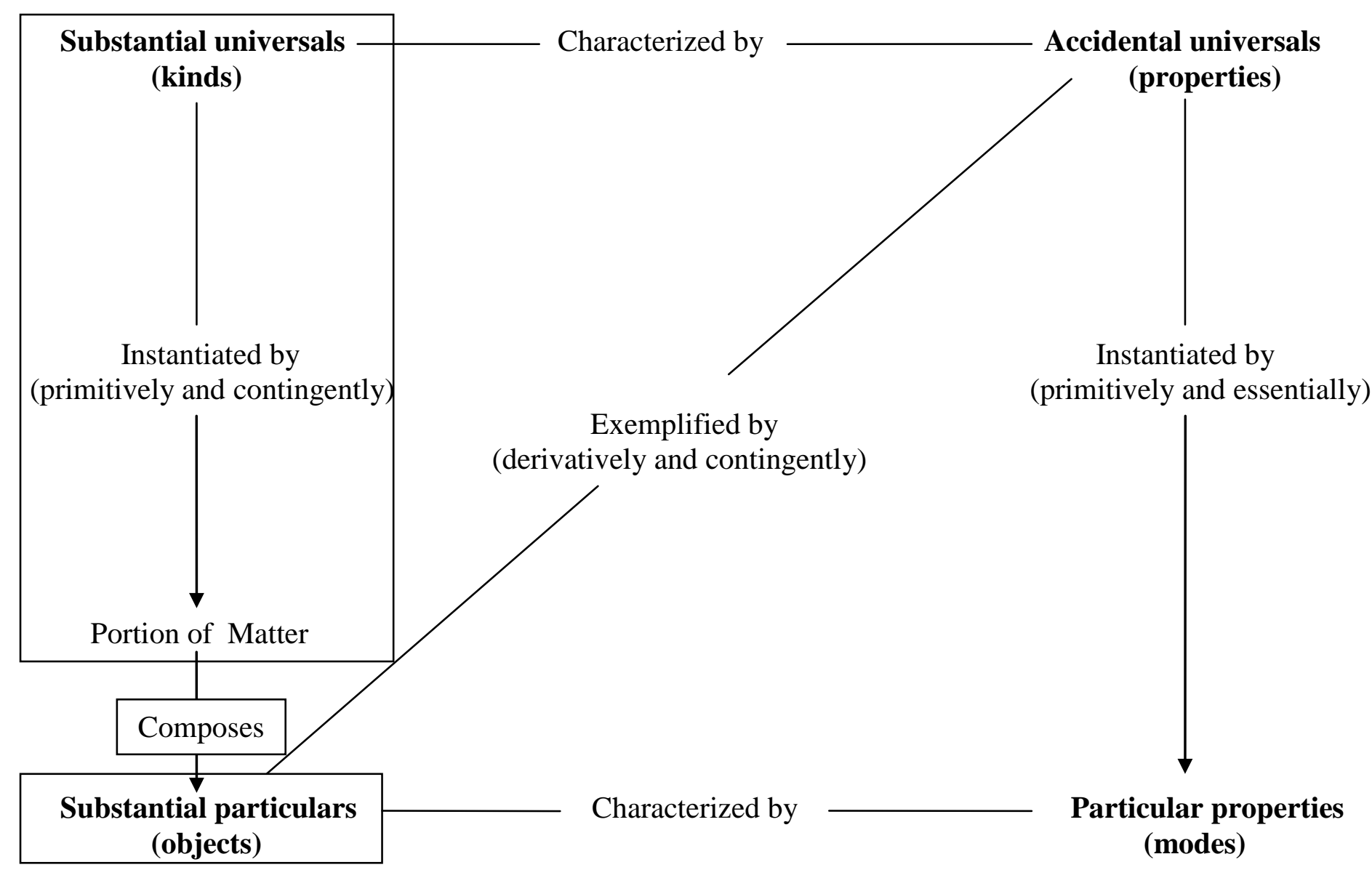




\section{REFERENCES}

Adams, R.M. (1979), 'Primitive Thisness and Primitive Identity', The Journal of Philosophy 76(1): 5-26.

Adams. R.M. (1981), 'Actualism and Thisness', Synthese 57: 3-42.

Adams, R.M. (1986), ‘Time and Thisness', Midwest Studies in Philosophy 11: 315-29.

Armstrong, D.M. (1999), 'Universals as Attributes' in Kim, J. and Sosa, E. (eds.)

Metaphysics: An Anthology, Oxford: Blackwell: 198-208.

Bennett, J. (1988), Events and their Names, Cambridge: Cambridge University Press.

Cleland, C. (1991), 'On the Individuation of Events', Synthese 86: 229-54.

David, M. (2009), 'Defending Existentialism?' in Reicher, M. (ed.) States of Affairs, Frankfurt: Ontos Verlag: ch. 8.

Diekemper, J. (2005), 'Presentism and Ontological Symmetry', The Australasian Journal of Philosophy 83(2): 223-40.

Diekemper, J. (2009), ‘Thisness and Events', The Journal of Philosophy 106(5): 255-76.

Diekemper, J., 'The Existence of the Past' (manuscript).

Hoffman, J. and Rosenkrantz, G. (2003), 'Platonistic Theories of Universals' in Loux, M.J. and Zimmerman, D.W. (eds.) The Oxford Handbook of Metaphysics, Oxford: Oxford University Press: 46-74.

Loux, M. (2006), 'Aristotle's Constituent Ontology' in Zimmerman, D. (ed.), Oxford Studies in Metaphysics ii, Oxford: Oxford University Press: ch. 8.

Lowe, E.J. (1998), The Possibility of Metaphysics: Substance, Identity, and Time, Oxford: Oxford University Press.

Lowe, E.J. (2000), 'Locke, Martin and Substance,' Philosophical Quarterly 50: 499-514.

Lowe, E.J. (2006), The Four-Category Ontology, Oxford: Oxford University Press.

Merricks, T. (2011), 'Singular Propositions' in Clark, K. and Rea, M. (eds.), Science,

Religion, and Metaphysics: New Essays on the Philosophy of Alvin Plantinga, Oxford:

Oxford University Press: ch. 4.

Mulligan, K., Simons, P., and Smith, B. (1984), 'Truth-Makers', Philosophy and Phenomenological Research 44: 287-321.

Plantinga, A. (1976), ‘Actualism and Possible Worlds', Theoria 42: 139-60. 
Plantinga, A. (1983), 'On Existentialism', Philosophical Studies 44(1): 1-20.

Rosenkrantz, G. (1993), Haecceity:: An Ontological Essay (Philosophical Studies Series v. 57), Dordrecht: Kluwer.

Wedin, M.V. (2000), Aristotle's Theory of Substance: The Categories and Metaphysics Zeta, Oxford: Oxford University Press.

Williamson, T. (2002), 'Necessary Existents' in O'Hear, A. (ed.), Logic, Thought, and Language, Cambridge: Cambridge University Press: 233-51. 